\title{
Disposable coffee capsules as a source of recycled polypropylene
}

\author{
Michel Lincoln Bueno Domingues¹, Jean Rodrigo Bocca', Silvia Luciana Fávaro' \\ and Eduardo Radovanovic ${ }^{2 *}$ (1)
}

\begin{abstract}
'Departamento de Engenharia Mecânica - DEM, Universidade Estadual de Maringá - UEM, Maringá, PR, Brasil ${ }^{2}$ Departamento de Química - DQI, Universidade Estadual de Maringá - UEM, Maringá, PR, Brasil

*eradovanovic@uem.br
\end{abstract}

\begin{abstract}
In this paper was investigated the chemical, physical, thermal, mechanical and morphological characteristics of the recyclable materials obtained of the NESCAFE ${ }^{\circledR}$ DOLCE GUSTO ${ }^{\circledR}$ branded beverage capsules, characterizing different resulting compositions. The characterization was made by following techniques: Fourier-transform infrared spectroscopy (FTIR), X-ray Diffraction (XRD), Differential Scanning Calorimetry (DSC), Thermogravimetric Analysis (TGA), Scanning Electron Microscopy (SEM), Water Absorption and techniques for the analysis of mechanical properties (tensile and impact test). The results showed that the body of the capsule and the inner filter, both made of polypropylene, are the most interesting materials to be reused, having good properties, while the materials resulting from the mixtures of all the constituents in the beverage capsules presented decreased mechanical properties.
\end{abstract}

Keywords: disposable capsules, polypropylene, recycling, mechanical properties.

How to cite: Domingues, M. L. B., Bocca, J. R., Fávaro, S. L., \& Radovanovic, E. (2020). Disposable coffee capsules as a source of recycled polypropylene. Polímeros: Ciência e Tecnologia, 30(1), e2020009. https://doi.org/10.1590/01041428.05518

\section{Introduction}

Since 2010, when the patents which regulated coffee capsules and their machines, especially Nespresso ones, began to expire ${ }^{[1,2]}$, the capsules coffee consumption grew a lot in Brazil. This growth further increased when, in 2015, some manufacturers of coffee capsules settled in Brazil ${ }^{[2]}$; therewith, the products were no longer imported and became more accessible ${ }^{[3]}$. Because of the rush of daily life, the arising of espresso capsules made daily life easier. With a very simple system to use, providing individual portions with a variety of flavors, quality and affordability, the Brazilian Coffee Industry Association (ABIC) ${ }^{[4]}$ estimates that, up to 2020, the consumption of the beverage will grow 17.5 percent a year. This number represented 12000 tons of capsules only in 2017, and reached 16000 tons in 2019.

The growth was so fast that it seems that the manufacturers did not have time to prepare themselves for the environmental problem caused by the incorrect disposal of the capsules. The small capsules, which typically take in their composition plastic, aluminum, and organic material (coffee, milk, chocolate, etc), are not easily recycled. Technically they would be, if people who own these machines had the time and predisposition to separate the parts of the capsules and collect the aluminum, the plastic and the organic material separately, before throwing them into the trash. But, given the idea that those who buy this type of product does it precisely to save time, it is highly unlikely for it to happen.

Companies claim that their products are recyclable, but the problem is that, for this to happen, the capsules need to be collected and the recyclable materials need to be treated separately, and, even having ability to recycle $60 \%$ to $75 \%$ of the capsules sold in Brazil, the rate of return is only $11 \%$, according to the Cafeicultura magazine ${ }^{[5]}$.

The problem is so serious that, in the year 2016, the German city of Hamburg banned the consumption of coffee in capsules in public agencies, citing the difficulty of recycling the waste as the reason of the decision.

In Brazil, the National Policy on Solid Waste ${ }^{[6]}$ says that the manufacturer is responsible for the destination of the waste originated from its products, and the companies, in compliance with the legislation, must have collection points, but those are concentrated only in the main cities of the country.

At present, the mechanical recycling is the most used one $^{[7]}$ and it consists of the selective collection, screening of the polymers with the best purity, grinding, washing with water (containing detergent or not), drying and reprocessing ${ }^{[8]}$, but due to the complexity of the capsules, often a mixture of plastic and aluminum, combined with the organic residues of coffee or other compounds according to the product, it becomes difficult to have the standard recycling process present in municipal organs. In this way, even though they are made of totally recyclable materials, the destination of the capsules are the common trash cans, most of the times, 
since there are not specific collection points throughout the country ${ }^{[9]}$.

Polypropylene is one major plastic that is used to produce a lot of single-use products. PET and polyethylene must be included in this category also ${ }^{[10]}$. In case of PP, the main strategy to reduce its presence in landfills is the mechanical recycling ${ }^{[11]}$. In general, the products made with recycled PP present downgrade properties, and must be used in less demanding applications. The decrease in properties is not only due to heating process of mechanical recycling but based on the source of PP. PP containing other plastics and contaminants, is the main drawback to its properties ${ }^{[12]}$. To minimize this fact a lot of researches were developed producing composites, nanocomposites, blends with other polymers and with raw PP, changing the melt-flow index (MFI) characteristics with additives, etc. ${ }^{[13,14]}$ In this case, mechanical properties, thermal properties, morphology, durability and process ability are studied and compared with raw materials. Another way to improve the characteristics of products made from recycled PP is to ensure its origin. Three questions are important: is the $\mathrm{PP}$ a only one component, is the PP clean or contaminated with inorganic components, and, if PP came from a blend, is the blend composition well known? ${ }^{[15]}$ Kozderka et al. ${ }^{[16]}$ studied the recycling of polypropylene in the automotive industry. The authors concluded that the main difference between virgin and recycled high impact polypropylene used in this industry is based mainly in the production process itself and higher electricity consumption for recycling, with no deterioration in properties, even before the $6^{\text {th }}$ reprocessing. Luna et al. ${ }^{[17]}$ studied blends of copolymer polypropylene and recycled copolymer polypropylene obtained from industrial containers. They concluded that blends could contain up to $60 \%$ of recycled material by weight, maintaining quality and reducing the product final cost. Take this into account, this paper presents a proposal for separating all the components of a single-use coffee capsule. Moreover, will be presented the production of mixtures containing these components through the extrusion process and the characterization of materials formed by different combinations of polypropylene, PET and aluminum, in order to enable final materials with different compositions and properties, with new possibilities for reusing this material that currently piles up in landfills worldwide.

\section{Experimental Section}

\subsection{Materials}

To the characterization of the materials, polymeric specimens were obtained after disassembling the Dolce Gusto NESCAFÉ ${ }^{\circledR}$ capsules, and these specimens were produced through the extrusion processes followed by injection. The different parts of the capsules (body, lid, aluminum filter and plastic filter), which are shown in Figure 1, were separated and constructed six different materials with different compositions of the constituent materials.

\subsection{Methodology}

The components of the capsules were grounded in a knife mill to particle size of about $2 \mathrm{~mm}$ and proportionally blended according to Table 1 . The samples were processed in a Thermo Scientific MiniLab II HAAKE Rheomex CTW 5 twin-screw extruder, with conical screws, operating in the corrotation mode, using a screw temperature of $190^{\circ} \mathrm{C}$, at a speed of $70 \mathrm{rpm}$ in a $5 \mathrm{~min}$ recirculation time.

The test specimens for the mechanical testing were processed in a Thermo Scientific HAAKE MiniJet II injection

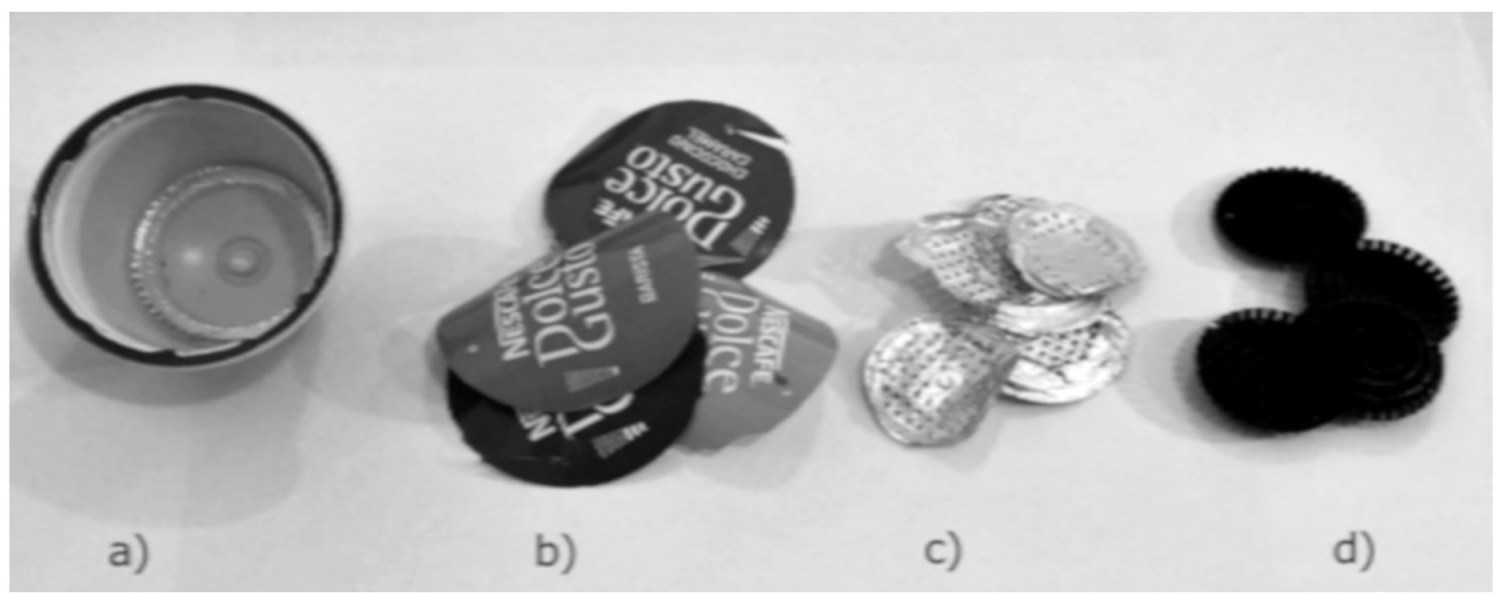

Figure 1. (a) Body, (b) Lid, (c) Aluminum filter and (d) Plastic filter of the disposable capsules.

Table 1. Composition of the test specimens concerning their mass.

\begin{tabular}{clcccc}
\hline sample & \multicolumn{1}{c}{ Composition } & Body & Lid & Aluminium filter & Plastic filter \\
\hline A1 & Body of the capsule & $96.4 \%$ & $2.5 \%$ & $1.1 \%$ & - \\
A2 & body + plastic filter & $72.0 \%$ & $1.9 \%$ & $0.8 \%$ & $25.3 \%$ \\
A3 & body + plastic filter + aluminium filter & $67.9 \%$ & $7.4 \%$ & $1.8 \%$ & $22.9 \%$ \\
A4 & body + plastic filter + aluminium filter + lid & $65.4 \%$ & $9.1 \%$ & $2.6 \%$ & $22.9 \%$ \\
A5 & body + plastic filter + lid & $66.6 \%$ & $9.3 \%$ & $0.8 \%$ & $23.3 \%$ \\
A6 & plastic filter & - & - & - & $100 \%$ \\
\hline
\end{tabular}


molding machine, with a cannon temperature of $210^{\circ} \mathrm{C}$, a mold temperature of $40^{\circ} \mathrm{C}$, an injection pressure of 450 bar, an injection time of $15 \mathrm{~s}$, holding pressure of $300 \mathrm{bar}$ and holding pressure time of $30 \mathrm{~s}$. The dimensions have followed the standard test method ASTM D638-14 for the tension, the ASTM D256 for the Izod Impact and the ASTM D570-98 for the water absorption specimens. 7 test specimens were prepared for the tensile testing, 5 test specimens for the impact test and 3 specimens for the water absorption test for each sample.

The materials characterization was performed through the following techniques: Fourier-transform infrared spectroscopy (FTIR) in a HATR accessory in a Thermo Fisher Scientific Nicolet iS10 FTIR equipment, in the spectral window of 4000-400 $\mathrm{cm}^{-1}$, in a resolution of $2 \mathrm{~cm}^{-1}$. X-ray diffraction (XRD) in a Shimadzu D6000 equipment using $\mathrm{Cu}$ source, $40 \mathrm{kV}$ voltage, a current of $30 \mathrm{~mA}, 2 \% \mathrm{~min}$ speed and angle of incidence, $2 \Theta$, between $10^{\circ}$ and $40^{\circ}$. Differential scanning calorimetry (DSC), to determine the crystalline melting temperature $(\mathrm{Tm})$ and the degree of crystallinity $(\chi c)$ in the Thermal Analyzer Q20(TA Instruments) equipment under an atmosphere of nitrogen at $50 \mathrm{~mL} / \mathrm{min}$, with a heating rate of $10^{\circ} \mathrm{C} / \mathrm{min}$, at the temperature range from 30 to $300^{\circ} \mathrm{C}$. Scanning electron microscopy (SEM), in which the fractured samples by the IZOD impact test were previously metallized with gold and observed in a Quanta FEI equipment, operating at $10 \mathrm{kV}$. Thermogravimetric analysis (TGA) was performed with the Thermal Analyzer Q50 (TA Instruments) equipment, operating at a heating rate of $10^{\circ} \mathrm{C} / \mathrm{min}$ from room temperature to $430{ }^{\circ} \mathrm{C}$, with compressed air flow at $50 \mathrm{~mL} / \mathrm{min}$. Water absorption according to the standard test method ASTM D570 and Mechanical Analysis, in which tension tests were performed in a universal testing machine EMIC DL 10000 with 5000 N load cell, in accordance with ASTM D638, at a speed of $10 \mathrm{~mm} / \mathrm{min}$ and impact resistance tests, carried out in a CEAST Resil Impactor Junior equipment with a $2.75 \mathrm{~J}$ pendulum, according to ASTM D256.

\section{Results and Discussion}

After separating the materials present in the disposable capsules, six different sample compositions, named herein A1, A2, A3, A4, A5 and A6 (Table 1), were prepared. The samples were not produced randomly; they were constituted by the possibilities of mixture among the beverage capsules materials, having samples composed only by the body of the capsule (A1), the body plus the plastic filter (A2), the body plus the plastic filter and the aluminum filter (A3), by the complete capsule (A4), the body plus the plastic filter and the lid (A5) and, finally, only by the plastic filter (A6).

\subsection{FTIR-HATR analysis}

The FTIR-HATR analyses were performed on the surface of the constituent parts of the Dolce Gusto NESCAFÉ ${ }^{\circledR}$ disposable capsule, namely the body of the capsule, the lidding film and the inner plastic filter. Both the body and the lidding film were analyzed on both sides, internal and external. Figure 2 and 3 show the FTIR spectra of these parts present in the disposable capsule. Through these analyses, it is clear that the main polymer that forms the parts of the capsule is the polypropylene, a fact confirmed by the presence of the characteristic peaks of asymmetric and symmetric stretch of the $\mathrm{C}-\mathrm{H}$ bond of $\mathrm{CH}_{3}$ groups (asymmetric at $2950 \mathrm{~cm}^{-1}$ and symmetric at $2865 \mathrm{~cm}^{-1}$ ), $\mathrm{CH}_{2}$ (asymmetric at $2916 \mathrm{~cm}^{-1}$ and symmetric at $2837 \mathrm{~cm}^{-1}$ ) and $\mathrm{CH}$ (shoulder at $2900 \mathrm{~cm}^{-1}$ ), as well as characteristic peaks of deformation vibrations in the $\mathrm{CH}_{3}$ groups at $1454 \mathrm{~cm}^{-1}, \mathrm{CH}_{2}$ at $1375 \mathrm{~cm}^{-1}$ and $\mathrm{CH}$ at $1358 \mathrm{~cm}^{-1}$, as described in the literature ${ }^{[18]}$.

Thereby, both the capsule, the inner filter and the inner part of the lid are made of polypropylene. The external part of the lidding film is composed of PET, through the comparison of its spectrum with spectra of the literature ${ }^{[19]}$. This formation of the PP/PET double layer film has the function of sealing the capsule through the fusion and adhesion of the lidding film of PP to the PP of the capsule, as well as the function of a gas barrier, acting on sealing the coffee on the inside of the capsule, generated by PET.

A detail to be noted in the FTIR analysis of the polypropylene (PP) of the capsule is the presence of small peaks in the region of $1742 \mathrm{~cm}^{-1}$. Peaks in this region are typical of $\mathrm{C}=\mathrm{O}$ groups, and are not expected to PP. The PP of the filter and the lidding film does not exhibit these peaks. One possibility of allocation of these peaks is that

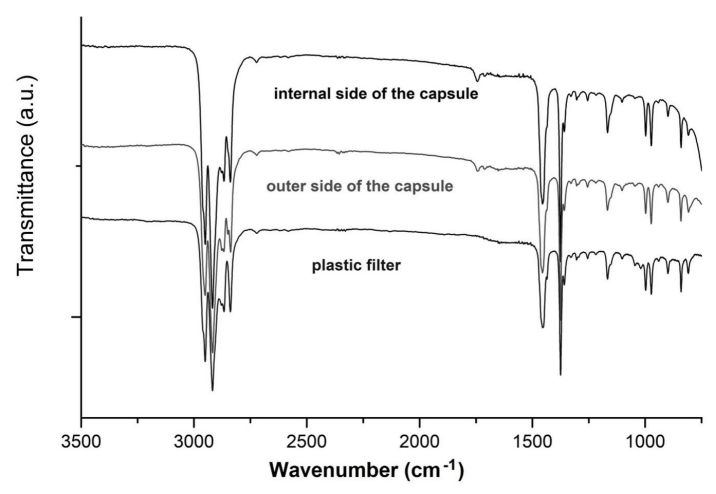

Figure 2. FTIR-HATR spectra of the body of the disposable capsules.

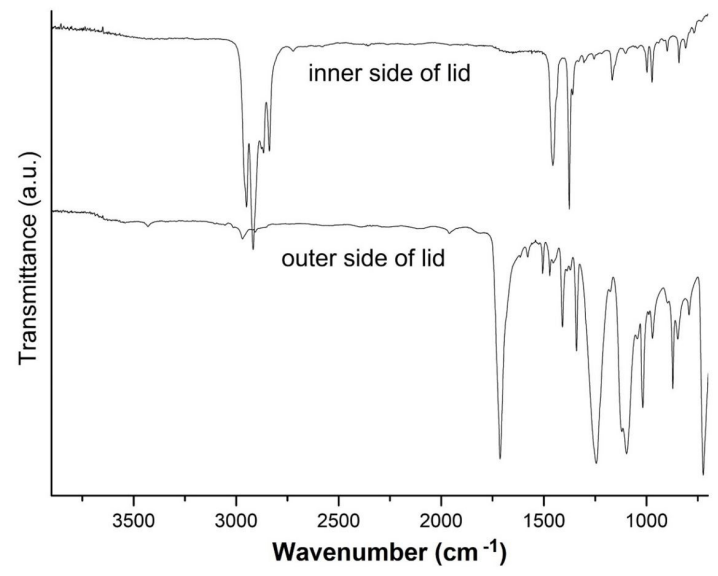

Figure 3. FTIR-HATR spectra of the lidding film - internal and external side - of the disposable capsules. 
they belong to a second phase ${ }^{[20]}$, probably an elastomeric phase. No other characteristic peaks of this component were identified in the spectrum, probably because they are less intense or in coincidence with PP peaks. Typical elastomeric phases that present $\mathrm{C}=\mathrm{O}$ groups are thermoplastic copolyester elastomers and thermoplastic polyurethanes ${ }^{[21]}$.

\subsection{X-ray diffraction (XRD) analyses}

The results of the X-ray diffraction analyses of the samples (A1, A2, A3, A4, A5 and A6) are shown in Figure 4. It is possible to observe the presence of the peaks corresponding

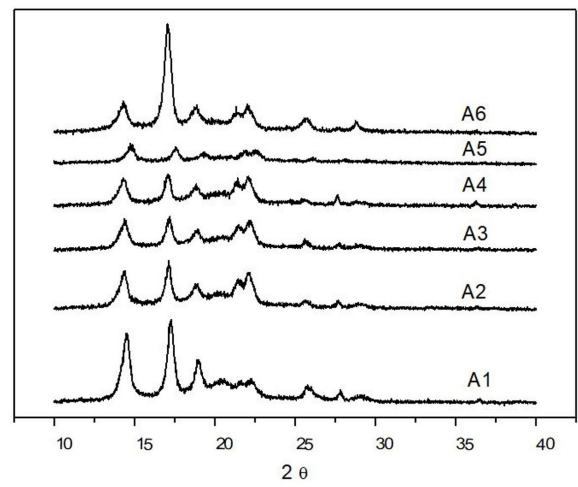

Figure 4. XRD analyses of samples A1 to A6.

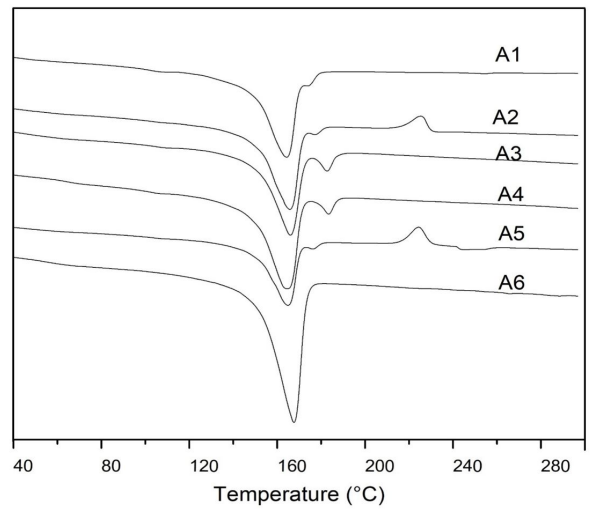

Figure 5. DSC analyses of A1, A2, A3, A4, A5 and A6 samples. to the crystallographic plans (110), (040), (130), (111), (131) and (041) very close to the Bragg angles (20): $14.2^{\circ}$, $17.0^{\circ}, 18.5^{\circ}, 21.3^{\circ}$ and $22.0^{\circ}$, which are typical of the isotactic polypropylene ${ }^{[22,23]}$. Table 2 shows the exact angles presented by each sample.

The variation of the diffraction angles may be related to changes in the crystalline structure of the material, but it may also be related to the difference in the positioning and thickness of the samples in the XRD sample holder, which would cause a displacement in the acquisition angle. It was only possible to identify a very small peak at $\sim 38^{\circ}$ related to the presence of metallic aluminium ${ }^{[24]}$, probably due to the low amount of this material in the mixture. The peaks relative to the planes (110) and (040) presented a relation of similar intensities in the samples from A1 to A5, however the sample A6 presented a much more intense peak relative to the plane (040), what indicates a difference in the crystalline organization of this material in relation to the other parts of the capsule, concerning the polypropylene. The sample A6 consists only of PP of the internal filter, and it should be remembered that this material presented FTIR spectrum with no signals related to the $\mathrm{C}=\mathrm{O}$ groups.

\subsection{Differential Scanning Calorimetry (DSC) analyses}

The results of the DSC analyses are shown in Figure 5 and Table 3. Through them, it is possible to verify that there were no significant changes in the melting temperature of the samples A1 to A5, however, the sample A6 presented a significantly higher melting temperature, ranging from 2 to $3{ }^{\circ} \mathrm{C}$, in the comparison with the other samples. As to the degree of crystallinity, samples A1, A2, A3 and A4 presented close values, showing that the presence of the aluminum filter, the plastic lid and the polypropylene filter does not change drastically the characteristics of crystallinity of these samples. It should be noted that both the plastic lid and the filter are also mostly made of polypropylene. However, the sample A6 presented a high degree of crystallinity, which agrees with what was expected, because it was pure PP, as shown by the FTIR results. In addition, samples from A1 to A5 presented a small endothermic peak between 175 and $185^{\circ} \mathrm{C}$, a little higher than the melting temperature of the PP, what may be related to the presence of second phase material on these samples. As elastomers

Table 2. Angles of the crystalline planes of the samples A1 to A6.

\begin{tabular}{|c|c|c|c|c|c|c|c|}
\hline Plans & Isotactic PP & A1 & A2 & A3 & A4 & A5 & A6 \\
\hline (110) & $14.20^{\circ}$ & $14.48^{\circ}$ & $14.32^{\circ}$ & $14.38^{\circ}$ & $14.28^{\circ}$ & $14.80^{\circ}$ & $14.28^{\circ}$ \\
\hline$(040)$ & $17.00^{\circ}$ & $17.26^{\circ}$ & $17.12^{\circ}$ & $17.18^{\circ}$ & $17.08^{\circ}$ & $17.56^{\circ}$ & $17.04^{\circ}$ \\
\hline (130) & $18.50^{\circ}$ & $18.90^{\circ}$ & $18.78^{\circ}$ & $18.78^{\circ}$ & $18.76^{\circ}$ & $19.22^{\circ}$ & $17.86^{\circ}$ \\
\hline (111) & $21.30^{\circ}$ & $21.50^{\circ}$ & $21.38^{\circ}$ & $21.40^{\circ}$ & $21.42^{\circ}$ & $21.80^{\circ}$ & $21.32^{\circ}$ \\
\hline$(131)(041)$ & $22.00^{\circ}$ & $22.12^{\circ}$ & $22.02^{\circ}$ & $22.06^{\circ}$ & 22.02 & 22.52 & $22.00^{\circ}$ \\
\hline
\end{tabular}

Table 3. Sample melting temperatures.

\begin{tabular}{|c|c|c|c|}
\hline Sample & $\mathrm{T}_{\mathrm{m}}\left({ }^{\circ} \mathrm{C}\right)$ & $\Delta H(J / g)$ & Crystallinity (\%) \\
\hline A1 & 164.3 & 67 & 40 \\
\hline A2 & 165.6 & 65 & 39 \\
\hline A3 & 165.9 & 62 & 38 \\
\hline A4 & 164.3 & 70 & 42 \\
\hline A5 & 164.8 & 63 & 38 \\
\hline A6 & 167.5 & 108 & 65 \\
\hline
\end{tabular}


for plastics are generally another polymer, this peak can be related to the melting of the second phase. Generally, the presence of a dispersed elastomeric phase in a PP matrix contributes to toughening ${ }^{[25,26]}$. The samples A2 and A5 showed exothermic peaks around $225^{\circ} \mathrm{C}$, and they may be related to the process of cold crystallization of amorphous PET ${ }^{[16]}$. PET can be present in all samples (except A6) by adding the lids containing this polymer, or even the small amount of PET remaining adhered to the capsule after cutting the central part of the lid, separating it from the body of the capsule. As the DSC analysis involves a small fraction of the sample $(\sim 10 \mathrm{mg})$, the presence or absence of PET, which is found in small quantities, is random. As already reported, the presence of a second phase or other contaminants in PP decrease the crystallinity to values close to $40 \%{ }^{[13,19,23]}$, as observed here to samples A1 to A5 (Table 3). The pure PP(A6) has the higher crystallinity, $65 \%$, in accordance with other recycled $\mathrm{PP}^{[17]}$.

\subsection{Scanning electron microscopy}

Scanning electron micrographs of sample A1 (body of the capsule) are shown in Figure 6A and 6B. These images were acquired from the broken face of the specimens submitted to the Izod test procedure. Figure 6A shows a kind of fracture typical of a brittle-fracture plastic material. This result is expected for the Izod rupture test, a test in which the process of rupture of the specimen occurs in a truly short time, with no possibility of elastic deformation of PP. In addition, in Figure $6 \mathrm{~B}$, it is observed the presence of a second phase, formed by small wired particles not adhered to the PP matrix. This material may be related to the phase attributed to the presence of the elastomer, previously identified in the FTIR and DSC techniques. Second phase particles were pulled out during the Izod test, then is possible to observe well-adhered particles in the PP matrix and multiple voids can be identified in the SEM images in samples A1 to A5.

The scanning electron micrographs of samples A2, A3, A4 and A5 showed a behavior that is similar to the one presented by sample A1, that is, the separation of phase with a fibrillar and ball shaped second phase, however, some differences were observed, such as the presence of aluminum in the sample A3 and PET in A4 and A5, as observed in the Figures $7 \mathrm{~A}$ and $7 \mathrm{~B}$, respectively. It may be noted that the amount of balls or wires has decreased.

The scanning electron micrograph of sample A6 (plastic filter of the capsule) is presented in Figure 8. It was observed, in this in case, the complete absence of a second phase (elastomeric), and a typical fracture of PP submitted to the impact Izod.

In Figure 9, an image (a) and a spectrum (b) of analysis by EDS are presented, and a typical second phase particle present in the PP matrix was analyzed. It can be observed through the EDS spectrum that this material is full of oxygen atoms, as well as carbon. This analysis comes together and corroborates the possibility that this second phase is an elastomeric material. Other parts that presented the second phase were also analyzed, and, in all analyzes, it was possible to identify the presence of oxygen, what did not occur in the analysis of the PP matrix.

\subsection{Thermogravimetric Analysis (TGA)}

The thermal analyzes of samples A1, A2, A3, A4, A5 and A6 are shown in Figure 10. It was found that the samples composed of the mixtures, A1 to A5, showed an increase in the thermal degradation temperature of around 20 to $30{ }^{\circ} \mathrm{C}$ at $50 \%$ of mass loss, as compared to the sample containing PP only (A6). The presence of PET and aluminum may have acted to retard the thermal degradation

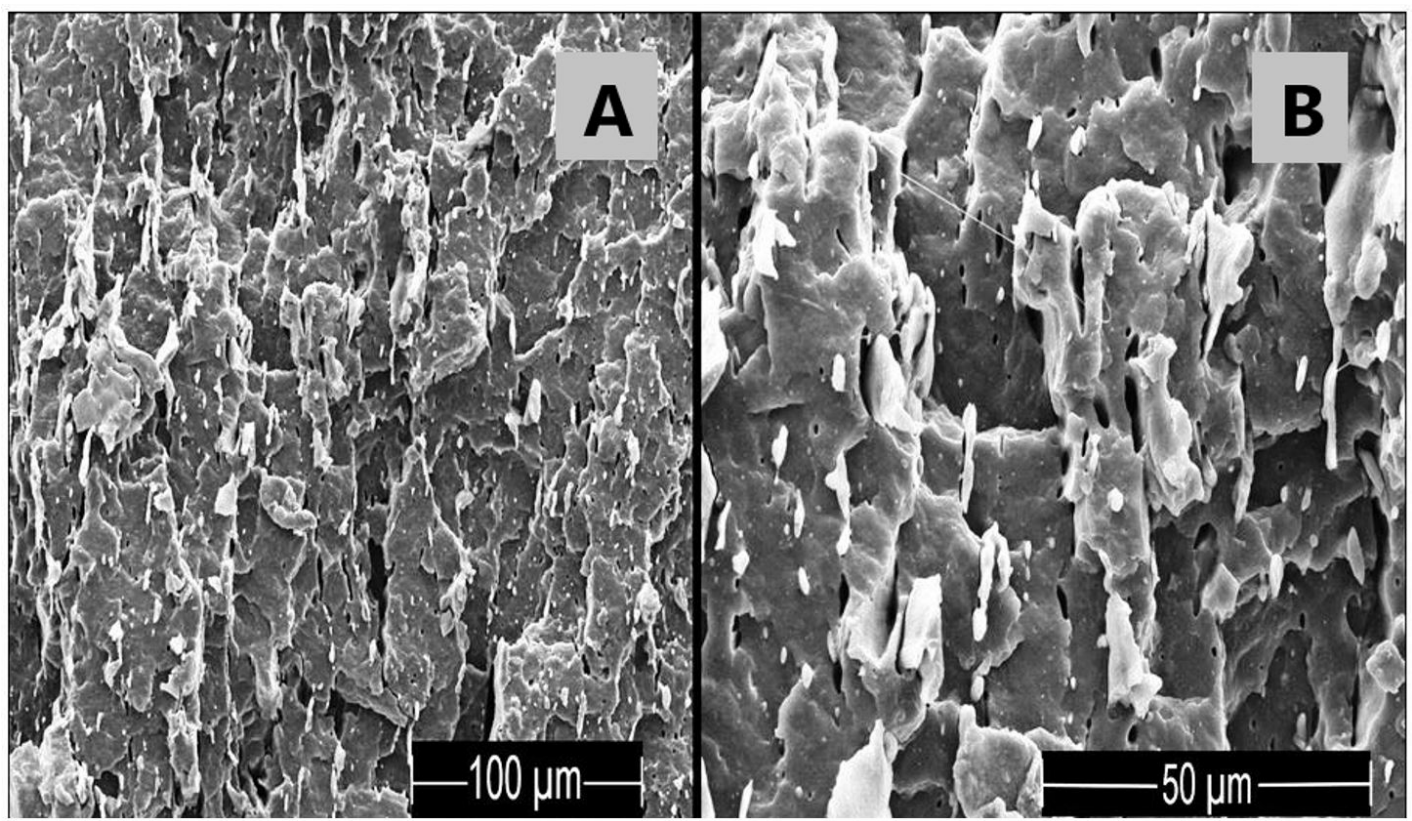

Figure 6. Scanning electron microscopy of the fractured region of sample A1. 


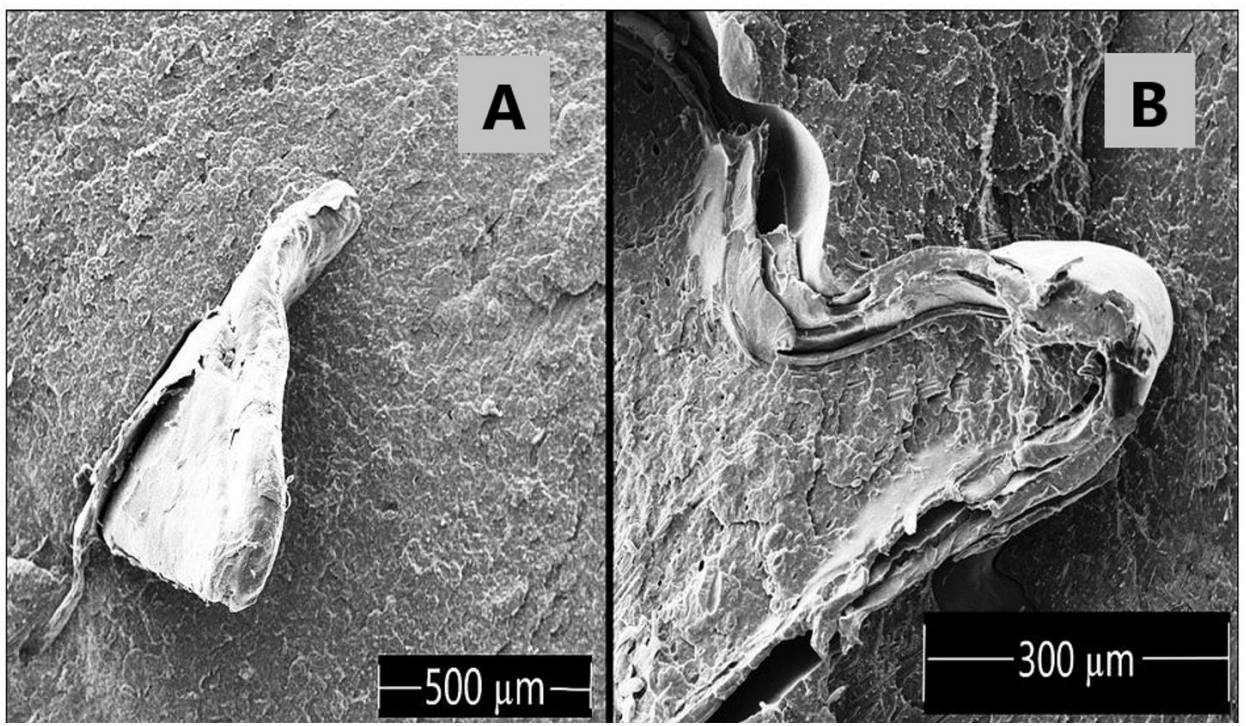

Figure 7. Scanning electron microscopy of the fractured region of sample A3 (A) and A4 (B).

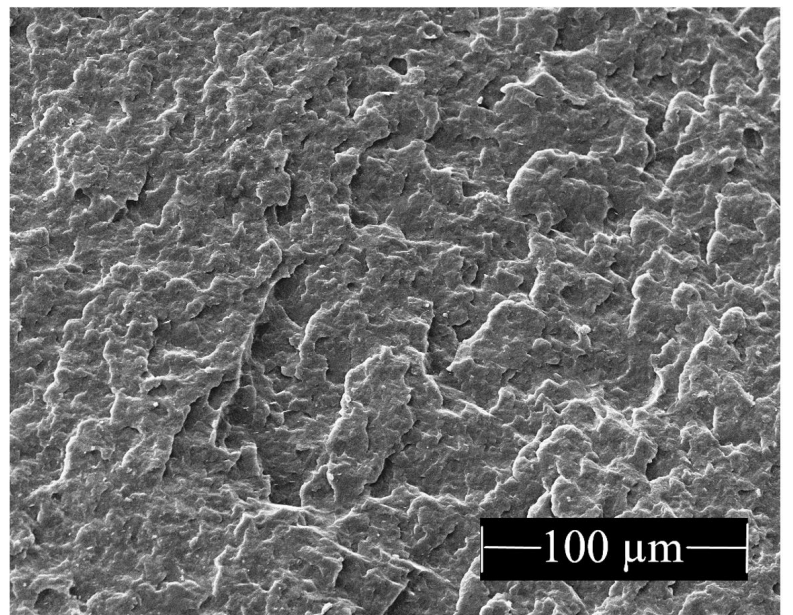

Figure 8. Scanning electron microscopy of the fractured region of sample A6.

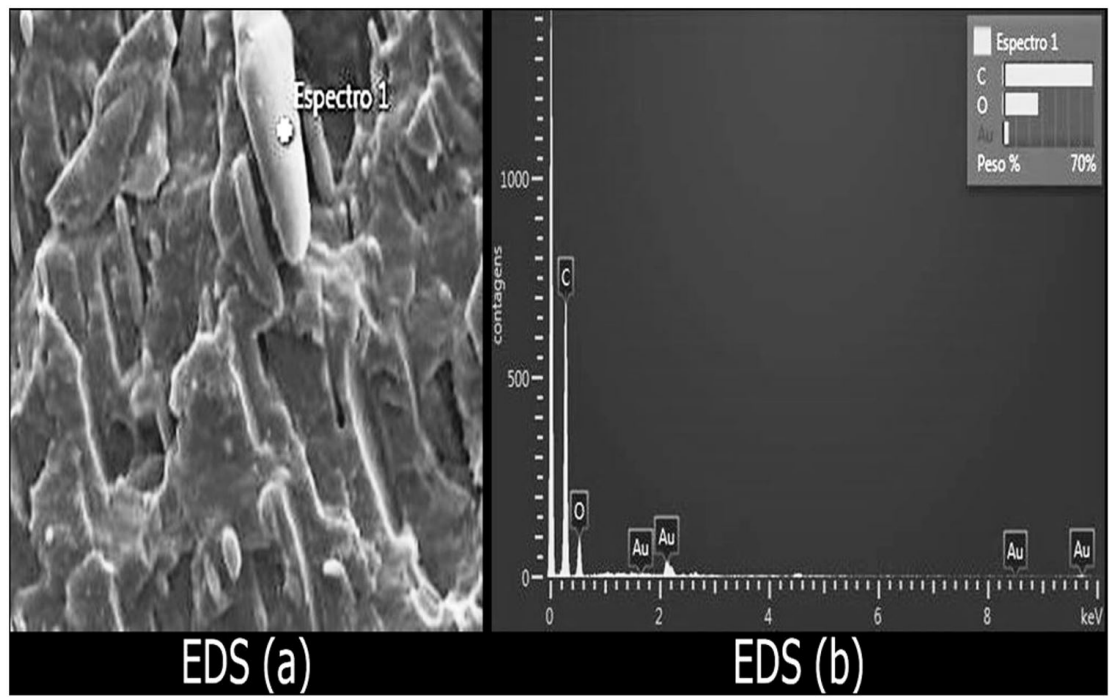

Figure 9. EDS analysis of sample A1. (a) image and (b) spectrum. 
process of PP. The amount of final waste, not degraded, gives an indication of the amount of aluminum present in composites, and it is always less than $5 \%$ concerning the initial mass. The curves relative to TGA analysis of A2 and A5 samples were suppressed from the Figure 10. They are in coincidence with results to A1 sample. Some researches stated that the enhancement of thermal stability of the PP in nanocomposites can be attributed to their higher degree of crystallinity ${ }^{[27,28]}$, however, in samples A1 to A5, the crystallinity is lower compared to A6 sample. A reasonable explanation to the higher thermal stability of impure PP is that the presence of aluminium in contact with PP could inhibit the degradation of polypropylene and catalyze the formation of carbonaceous char on the surface, significantly improving the thermal stability.

\subsection{Water absorption}

In accordance with the standard test method ASTM D570, for the analysis of the water absorption in the samples, a first weighing of the samples was performed after a period of one week and put again in a thermostatic bath for another week, in which the new weighing presented an increase of less than $1 \%$ in its weight, characterizing its saturation. As observed in Table 4, there was a small gain of water weight in all the samples, not exceeding $0.3 \%$ in any case. The sample which presented a lower water absorption was A6, followed by A5 and A1, a fact that was already expected for the samples A6 and A1, since A6 is composed exclusively of PP and A1 presents mostly PP, and the process of water absorption is probably related to the presence of aluminum, PET and defects created by these materials in the PP matrix.

\subsection{Mechanical analysis}

The stress-strain curves (typical) of the six samples analyzed by the tensile testing are shown in Figure 11. Similar behavior is clearly observed in relation to the tensile strength in the six samples; however, the maximum strain varies greatly.

As it deals with blends or even composites, if elastomeric, aluminum and PET phases are considered as materials that interfere with the mechanical properties of the PP matrix, the interface and the adhesion between the phases and reinforcement mechanisms influenced the mechanical properties causing variations in those ones. These variations are evident in Table 5, which presents values obtained from the tensile test versus strain for the six samples.

The Young's Modulus values of the six samples are below the expected for recycled $\mathrm{PP}^{[13,16]}$, probably due to the use of elastomeric phase that cause some changes in the final properties of the products, among them the reduction of stiffness, or the poor adhesion between PP and aluminium or PET. Samples A3 and A4 showed the largest differences in relation to the average Young's Modulus values of all samples, what may be a consequence of the poor interaction between the matrix phase, polypropylene and the dispersed phase, aluminum, in the case of sample A3. However, for the

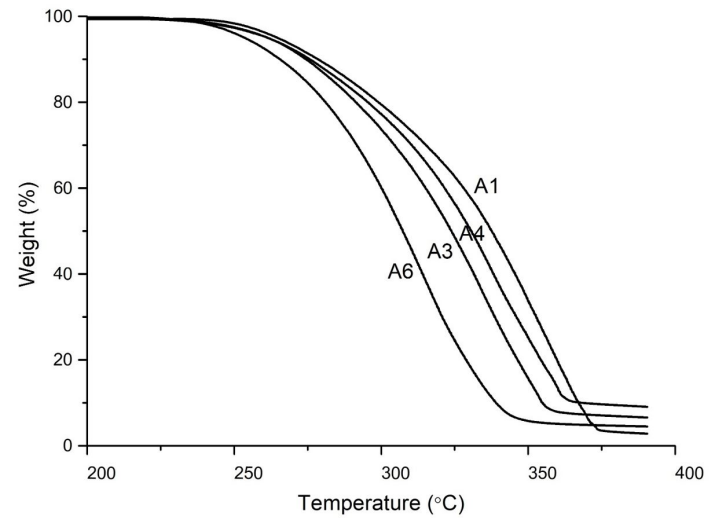

Figure 10. Thermogravimetric analysis of samples A1, A3, A4 and $\mathrm{A} 6$.

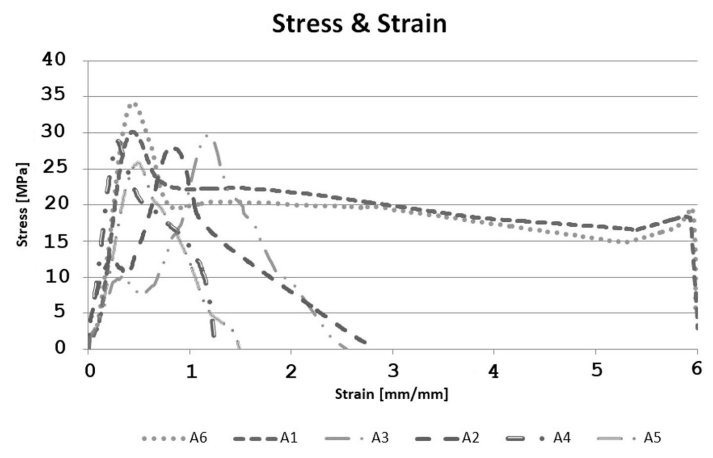

Figure 11. Stress and Strain typical-curves for A1 to A6 samples.

Table 4. Water absorption analysis of samples A1 to A6.

\begin{tabular}{|c|c|c|c|c|c|c|}
\hline Sample & A1 & A2 & A3 & A4 & A5 & A6 \\
\hline Average absorption after 1 week & $0.20 \%$ & $0.26 \%$ & $0.24 \%$ & $0.24 \%$ & $0.20 \%$ & $0.15 \%$ \\
\hline Average absorption after 2 weeks & $0.25 \%$ & $0.30 \%$ & $0.28 \%$ & $0.28 \%$ & $0.24 \%$ & $0.19 \%$ \\
\hline
\end{tabular}

Table 5. Values of tensile strength $(\sigma)$, Young's Modulus $(E)$, Yield point $(\sigma f)$, ductility in terms of strain $(\varepsilon)$, toughness $\left(u_{t}\right)$ and resilience $\left(u_{r}\right)$.

\begin{tabular}{cccrcrl}
\hline Sample & $\boldsymbol{\sigma}_{\text {max }}(\mathbf{M P a})$ & $\mathbf{E}(\mathbf{M P a})$ & $\boldsymbol{\sigma}_{\mathbf{f}}(\mathbf{M P a})$ & $\boldsymbol{\varepsilon}(\mathbf{\%})$ & $u_{\mathbf{t}}\left(\mathbf{J} / \mathbf{m}^{3}\right)$ & $u_{\mathbf{r}}\left(\mathbf{J} / \mathbf{m}^{3}\right)$ \\
\hline A1 & $30.2( \pm 0.7)$ & $792( \pm 33)$ & $24.4( \pm 1.4)$ & $497.3( \pm 106.4)$ & $102.0( \pm 30.8)$ & $3.8( \pm 0.5)$ \\
A2 & $30.9( \pm 0.7)$ & $801( \pm 12)$ & $11.4( \pm 3.4)$ & $201.6( \pm 75.0)$ & $27.6( \pm 10.9)$ & $0.9( \pm 0.5)$ \\
A3 & $32.7( \pm 0.4)$ & $401( \pm 17)$ & $8.6( \pm 2.9)$ & $222.1( \pm 23.0)$ & $30.2( \pm 3.9)$ & $1.4( \pm 1.3)$ \\
A4 & $29.1( \pm 1.4)$ & $1157( \pm 11)$ & $23.0( \pm 1.4)$ & $162.9( \pm 32.3)$ & $23.6( \pm 4.5)$ & $2.2( \pm 0.6)$ \\
A5 & $29.5( \pm 1.4)$ & $655( \pm 9)$ & $25.8( \pm 1.5)$ & $120.3( \pm 20.6)$ & $17.1( \pm 2.9)$ & $5.2( \pm 0.7)$ \\
A6 & $34.3( \pm 0.4)$ & $866( \pm 36)$ & $31.5( \pm 1.7)$ & $611.2( \pm 146.0)$ & $117.7( \pm 30.5)$ & $5.9( \pm 0.5)$ \\
\hline
\end{tabular}


A4 sample, the increase in the amount of PET and aluminum was predominant in the Young's Modulus properties, with a significant increasing in the value, even when compared to the sample with pure PP. The sample A6 was the one that presented the smallest discrepancy among the values measured in the tests of the multiple specimens, what was already expected, since this sample is made of pure PP, not having the presence of aluminum or PET that can cause defects in the structure of the specimen.

It is possible to observe that all the samples had similar behavior in relation to the limit of tensile strength, showing that both the variation of the amount of the dispersed phase and the type of materials present did not significantly have an influence on this characteristic. This uniformity was not repeated in the other parameters. It is possible to verify different yield points, in which sample A6 presents the highest index, a consequence of the higher degree of crystallinity, and samples A2 and A3 with the worst indexes, a consequence of the presence of aluminum and PET.

To the ductility and toughness properties, it can be observed that samples A1 and A6 stand out positively, because they present larger relative quantities on polypropylene. The other samples were as expected for ductility, since polypropylene-based materials may show elongation between 100 to $700 \%{ }^{[29]}$, but both the toughness and ductility decrease due to the presence of aluminium and PET that tend to make defects in the specimens and cause a decrease in strength and a rupture at lower deformation values.

Regarding the resilience, the variations in the presented values can be explained by the thermomechanical effect that occurs during the process of preparation of the samples, generating possible processes of degradation in the polymer. Variables, such as the length and diameter of the extruder screw, thread profile and temperature used in the processing, may cause changes in material behavior. In this case, the presence of the aluminum and PET, may have had an influence on this characteristic; however, its effect was not clear.

The results of the Izod impact strength of samples A1, A2, A3, A4, A5 and A6 are shown in Figure 12. All samples presented increased impact resistance when compared to pure PP (sample A6). In this case, both the presence of elastomeric phase, aluminium and PET may have contributed to the absorption of impact energy and blocking of the process of crack propagation, improving the characteristics of impact strength of the materials, comparing to the expected results for polypropylene ${ }^{[12]}$.

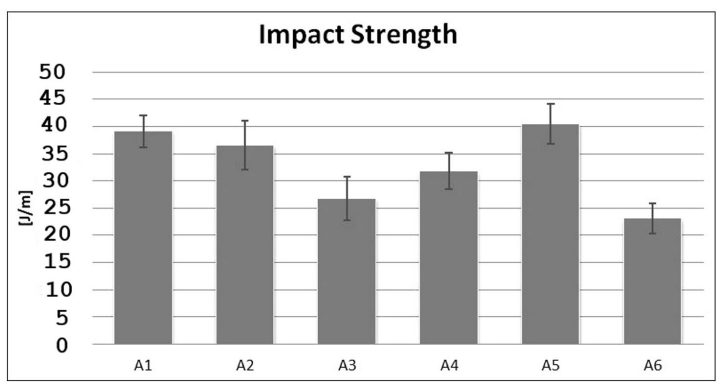

Figure 12. Izod impact strength values of samples A1 to A6.

\section{Conclusion}

The results of the chemical, physical, thermal, and morphological characterizations showed that the main constituent material of the body of the disposable capsules is the polypropylene. The mechanical characterization of the material obtained by mixing the recyclable materials of the disposable capsules showed that the polypropylene filter and the body of the capsule are the most interesting materials to be recycled, and those present good properties. The materials resulting from the mixture of all the constituent parts of the disposable capsule presented decreased mechanical properties compared to the samples composed only of the capsule or the PP filter, what is probably a consequence of the poor interactions between the polymer matrix and aluminum and PET. However, depending on the final application, all the material can be used in a process which reduces time and labor for the separation of the aluminum and the lid from the rest of the capsule parts.

\section{Acknowledgements}

The authors acknowledge to COMCAP - UEM for the FTIR, XRD, DSC and SEM analyses, and to Coordenação de Aperfeiçoamento de Pessoal de Nível Superior - CAPES and Conselho Nacional de Desenvolvimento Científico e Tecnológico - CNPq by scholarship.

\section{References}

1. O Negócio do Varejo Magazine. (2019). Retrieved in 2019, October 10, from http://onegociodovarejo.com.br/rivaisameacam-lideranca-da-nespresso-nas-capsulas-de-cafe/

2. Pacheco P. (2010). Todos querem ser um Nespresso - Com o fim de patente de cápsula, empresas lançam genéricos do café da Nestlé. O Estado de S. Paulo. In Revista Cafeicultura, Rio Paranaíba. Retrieved in 2019, October 10, from http:// revistacafeicultura.com.br/?mat $=34061$

3. Gontijo J. (2016). Com três fábricas, Montes Claros vira polo de café em cápsula. Belo Horizonte: O Tempo. Retrieved in 2019, October 10, from https://www.otempo.com.br/capa/ economia/com-tr\%C3\%AAs-f\%C3\%Albricas-montes-clarosvira-polo-de-caf\%C3\%A9-em-c\% $\%$ C3\%A1psula-1.1213345

4. Associação Brasileira da Indústria de Café - ABIC. (2019). Retrieved in 2019, October 10, from http://abic.com.br/ estatisticas/pesquisas/pesquisa-tendencias-do-mercado-de-cafe/

5. Diário do Comércio. (2017). Nespresso investe na reciclagem de cápsulas. In: Revista Cafeicultura, Rio Paranaíba. Retrieved in 2019, October 10, from http://revistacafeicultura.com. $\mathrm{br} /$ ?mat $=65407$

6. Brasil. Ministério do Meio Ambiente. (2019). Política Nacional de Resíduos Sólidos. Brasília: Ministério do Meio Ambiente. Retrieved in 2019, October 10, from www.mma.gov.br/ pol\%C3\%ADtica-de-res $\% \mathrm{C} 3 \%$ ADduos-s\%C3\%B3lidos

7. Franchetti, S. M., \& Marconato, J. C. (2003). A importância das propriedades físicas dos polímeros na reciclagem. Química Nova na Escola, 18, 42-45. Retrieved in 2019, October 10, from http://qnesc.sbq.org.br/online/qnesc18/A09.PDF

8. Portal Resíduos Sólidos. (2019). Retrieved in 2019, October 10, from http://www.portalresiduossolidos.com/reciclagemde-plasticos-polimeros

9. Nestlé Nespresso S.A. (2018). Retrieved in 2018, November 26, from https:/www.nespresso.com/positive/br/en\#map-results 
10. Dahlbo, H., Poliakova, V., Mylläri, V., Sahimaa, O., \& Anderson, R. (2018). Recycling potential of post-consumer plastic packaging waste in Finland. Waste Management (New York, N.Y.), 71, 52-61.http://dx.doi.org/10.1016/j.wasman.2017.10.033. PMid:29097129.

11. Hamad, K., Kaseem, M., \& Deri, F. (2013). Recycling of waste from polymer materials: an overview of the recent works. Polymer Degradation \& Stability, 98(12), 2801-2812. http:// dx.doi.org/10.1016/j.polymdegradstab.2013.09.025.

12. Jmal, H., Bahlouli, N., Wagner-Kocher, C., Leray, D., Ruch, F., Munsch, J. N., \& Nardin, M. (2018). Influence of the grade on the variability of the mechanical properties of polypropylene waste. Waste Management (New York, N.Y.), 75, 160-173. http:// dx.doi.org/10.1016/j.wasman.2018.02.006. PMid:29463419.

13. Zdiri, K., Elamri, A., Hamdaoui, M., Harzallah, O., Khenoussi, N., \& Brendlé, J. (2018). Reinforcement of recycled PP polymers by nanoparticles incorporation. Green Chemistry Letters and Reviews, 11(3), 296-311. http://dx.doi.org/10.1080/1751825 3.2018.1491645.

14. Bogataj, V. Ž., Fajs, P., Peñalva, C., Omahen, M., Čop, M., \& Henttonen, A. (2019). Utilization of recycled polypropylene, cellulose andnewsprint fibres for production of green composites. Detritus, 07, 36-43. http://dx.doi.org/10.31025/26114135/2019.13857.

15. Ragaert, K., Delva, L., \& Van Geem, K. (2017). Mechanical and chemical recycling of solid plastic waste. Waste Management (New York, N.Y.), 69, 24-58. http://dx.doi.org/10.1016/j. wasman.2017.07.044. PMid:28823699.

16. Kozderka, M., Rose, B., Bahlouli, N., Kočí, V., \& Caillaud, E. (2017). Recycled high impact polypropylene in the automotiveindustry - mechanical and environmental properties. International Journal on Interactive Design and Manufacturing, 11(3), 737-750. http://dx.doi.org/10.1007/s12008-016-0365-9.

17. Luna, C. B. B., Ferreira, E. S. B., Silva, L. J. M. D., Silva, W. A., Araújo, E. M., \& Melo, J. B. C. A. (2019). Blends with technological potential of copolymer polypropylene with polypropylene from post-consumer industrial containers. Materials Research Express, 6(12), 125319. http://dx.doi. org/10.1088/2053-1591/ab56b2.

18. Lin-Vien, D., Colthup, N. B., Fateley, W. G., \& Grasselli, J. G. (1991). The Handbook of infrared and raman characteristic frequencies of organic molecules. USA: Academic Press.

19. Favaro, S. L., Rubira, A. F., Muniz, E. C., \& Radovanovic, E. (2007). Surface modification of HDPE, PP and PET films with $\mathrm{KMnO}_{4} / \mathrm{HCl}$ solutions. Polymer Degradation \& Stability, 92(7), 1219-1226. http://dx.doi.org/10.1016/j. polymdegradstab.2007.04.005.
20. Sclavons, M., Laurent, M., Devaux, J., \& Carlier, V. (2005). Maleic anhydride-grafted polypropylene: FTIR study of a model polymergrafted by ene-reaction. Polymer, 46(19), 8062-8067. http://dx.doi.org/10.1016/j.polymer.2005.06.115.

21. Massey, L. K. (2006). The effects of UV light and weather on plastics and elastomers. USA: William Andrew Inc.

22. Machado, G. (2002). Estudo da morfologia e cristalinidade em polipropileno isotático submetido a deformação uniaxial em temperatura ambiente (Tese de doutorado). Universidade Federal do Rio Grande do Sul, Porto Alegre.

23. Iijima, M., \& Strobl, G. (2000). Isothermal crystallization and melting of isotactic polypropylene analyzed by time and temperature-dependence small-angle X-ray scattering experiments. Macromolecules, 33(14), 5204-5214. http:// dx.doi.org/10.1021/ma000019m.

24. Li, X., Yang, H., \& Li, Y-C. (2015). Characterization of thermal reaction of aluminum/copper (II) oxide/poly (tetrafluoroethene) nanocomposite by thermogravimetric analysis, differential scanning calorimetry, mass spectrometry and X-ray diffraction. Thermochimica Acta, 621, 68-73. http://dx.doi.org/10.1016/j. tca.2015.10.012.

25. Takemori, M. T. (1979). Towards an understanding of the heat distortion temperature of thermoplastics. Polymer Engineering and Science, 19(15), 1104-1109. http://dx.doi.org/10.1002/ pen.760191507.

26. Luna, C. B. B., Silva, D. F., Araújo, E. M., Mélo, T. J. A., \& Oliveira, A. D. (2017). Rheological, mechanical, thermomechanical and morphological behavior of polystyrene/ shoes residue blends with different granulometry. Tecnologica em Metalurgia, Materiais e Mineração, 14(3), 219-226. http:// dx.doi.org/10.4322/2176-1523.1111.

27. Maiti, P., Nam, P. H., Okamoto, M., Hasegawa, N., \& Usuki, A. (2002). Influence of Crystallizationon Intercalation, Morphology and Mechanical Properties of Polypropylene/ Clay Nanocomposites. Macromolecules, 35(6), 2042-2049. http://dx.doi.org/10.1021/ma010852z.

28. Salemane, M. G., \& Luyt, A. S. (2006). Thermal and Mechanical Properties of Polypropylene-Wood Powder Composites. Journal of Applied Polymer Science, 100(5), 4173-4180. http://dx.doi. org/10.1002/app.23521.

29. Callister, W. D. J. (2002). Ciência e Engenharia de Materiais. Uma Introdução. Rio de Janeiro: LTC.

Received: Feb. 26, 2020

Revised: Apr. 07, 2020

Accepted: Apr. 30, 2020 